\title{
Numerical Modeling of River Sedimentation: Application to the Rice Farming Lowlands of Sindou, Burkina-Faso
}

\author{
Bama Nati Aïssata Delphine ${ }^{1}$, Kouakou Ariel Michée ${ }^{2}$, Leye Babacar ${ }^{2}$ \\ ${ }^{1}$ Plant Production Department, Institute for the Environment and Agricultural Research (INERA), Ouagadougou, Burkina Faso \\ ${ }^{2}$ International Institute for Water and Environmental Engineering (2iE), Ouagadougou, Burkina Faso
}

\section{Email address:}

Nati_aissata@yahoo.fr (B. N. A. Delphine), nati.aissata@gmail.com (B. N. A. Delphine)

\section{To cite this article:}

Bama Nati Aïssata Delphine, Kouakou Ariel Michée, Leye Babacar. Numerical Modeling of River Sedimentation: Application to the Rice Farming Lowlands of Sindou, Burkina-Faso. Hydrology. Vol. 8, No. 4, 2020, pp. 62-68. doi: 10.11648/j.hyd.20200804.11

Received: October 18, 2020; Accepted: November 5, 2020; Published: November 27, 2020

\begin{abstract}
The development of the shallows has become essential in the fight against hunger in Burkina Faso. In addition, rivers there are subject to massive silting up caused by erosion. These sedimentary deposits tend to gradually reduce the flow section, thus promoting the retention of pollutants in streams. So in order to prevent this phenomenon, it is important to have tools to predict the evolution of sedimentation. The coupled equation of Shallow-water-Exner, treated from the complete system, was used in this study. Indeed, the complexity of the analytical resolution of this equation requires to adopt a numerical resolution. The finite volume method was chosen. The first step was to collect sedimentation data from the lowland of Sindou using locally made tools. Simulations are carried out in order to test the model's performance. Sensitivity analysis showed that the model is sensitive to disturbances in friction and slope parameters of the field. The results showed the tool's ability to simulate the sedimentation of actual unsatisfactory cases. In fact, bad appreciation of parameters, friction and the absence of the topographic data generate a large margin of error between the simulated and observed values showing a difference in the shape of the carried sediments curves.
\end{abstract}

Keywords: Lowland, Finite Volume Method, Streams, Equation Shallow-water-Exner, Sedimentation

\section{Introduction}

Sedimentation is a natural, geological phenomenon which is the result of erosion. There are several types of erosions such as water, wind, and soil-related erosion [1]. Water erosion is a natural phenomenon whose intensity varies depending on rainfall and current strength, but also on the nature of the soil, the slope and drainage of the land, and its exposure to bad weather [2]. There is a growing interest in the phenomenon of silting up of river. In the case of the Sourou River in Burkina Faso, Sedimentation and siltation are felt if not visible, but require further assessment to better appreciate their extent. Moreover, all rivers in Burkina Faso are strongly affected by this phenomenon resulting from the widespread degradation of land and ecosystems [3]. With this in mind, this study "Numerical modeling of river sedimentation", applied to lowland of Sindou, during wet season 2019, is being carried out as part of the CSA Burkina Faso project, funded by the German development corporation (GIZ). The technics used at the lowland are "smart-valleys" development [4-6], which have already proven their worth in Benin and Togo $[7,8]$. These technics will help mitigate the climate effects on producers. During this study, flow rate and sediment have been determinate. The sensitivity of friction parameters, topography and parameter Ag has been analyzed. And, performance of the model (through the data on sediments collected before at the various sites) has been tested in the aim to contribute to the knowledge of sedimentation of streams in the lowlands.

\section{Materials and Methods}

\subsection{Presentation of the Area}

The municipality of Sindou is located in the Cascade Region, belongs to the Leraba province. The municipality has an area of about $403.15 \mathrm{~km}^{2}$ and is located between the municipality of Douna and Kankalaba at $50 \mathrm{~km}$ from the city of Banfora. Our study area is located at the entrance of the commune near the peaks of Sindou tourist site. 


\subsection{Presentation of Soil Types}

The lowland of Sindou is situated in southwestern Burkina Faso. This area is made up of several types of soils, where their diversity is a strong potential for agricultural activity. This area is considered both as a granary and an orchard for the country. The main types of soils found there are:

Hydromorphic soils with pseudo-gley minerals located along streams.

Raw minerals soils. Observed on superficial formations that have not yet undergone a pedological evolution [9].

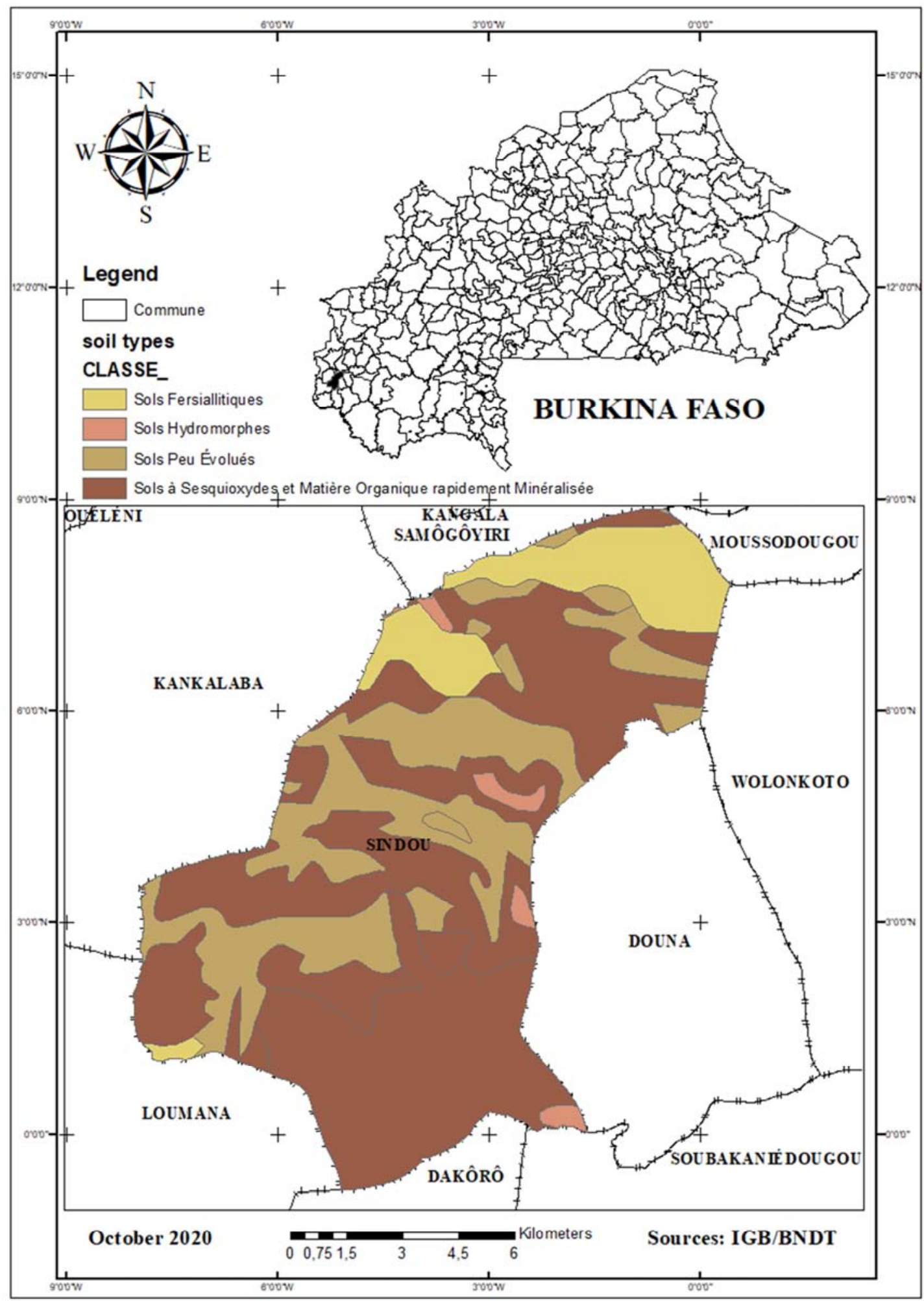

Figure 1. Soil map of the Sindou. 


\subsection{Characterization of Flow Rate}

The aim here is to determine the flood flows for the maximum rain event of 2019 at the Sindou site. This calculated flood rate will be used to run the model for real cases.

The methods used for debits are:

1) ORSTOM Method

$$
\mathrm{Q}_{\mathrm{r} 10}=\frac{\mathrm{AP}_{10} \mathrm{~K}_{\mathrm{r} 10} \propto_{10} \mathrm{~S}}{\mathrm{~T}_{\mathrm{b} 10}}
$$

$\mathrm{Q}_{10}=\mathrm{qQ}_{\mathrm{r} 10}$. With $\mathrm{q}$ a watershed-based coefficient

$\mathrm{Q}_{\mathrm{r} 10}$ : Peak flow of 10 -year surface runoff $\left[\mathrm{m}^{3} / \mathrm{s}\right]$;

A: VUILLAUME abatement coefficient;

$\mathrm{P}_{10}$ : Ten-year daily rain $[\mathrm{mm}]$;

$\mathrm{K}_{\mathrm{r} 10}$ : Ten-year runoff coefficient;

$\alpha$ : Peak coefficient of 10 -year flood;

$\mathrm{S}$ : Watershed area $[\mathrm{km} 2]$;

$\mathrm{T}_{\mathrm{b} 10}$ : 10-year flood baseline

2) Méthode RATIONNELLE

$$
Q_{10}=\frac{C_{r 10} * P_{10} * S}{3,6 * T_{C}}
$$

$\mathrm{P}_{10}$ : daily 10 -year rain

S: Watershed Area

$\mathrm{T}_{\mathrm{c}}$ : Concentration time

$\mathrm{Cr}_{10}$ : the runoff coefficient

3) Stream flows

$$
Q=K_{S} S R_{H}^{2 / 3} \sqrt{I},\left(\mathrm{~m}^{3} / \mathrm{s}\right)
$$

Ks Stricklerco efficient

a) $\mathrm{S}$ wet surface

b) $R_{h}$ Hydraulic radiation it is the ratio by being the section and perimeter $R_{h}=s / p(\mathrm{~m})$

c) I the slope of the stream $(\mathrm{m} / \mathrm{km})$

d) $\mathrm{n}$ coefficient de Manning.

Characterization of sedimentation

4) Device for sedimentation sample

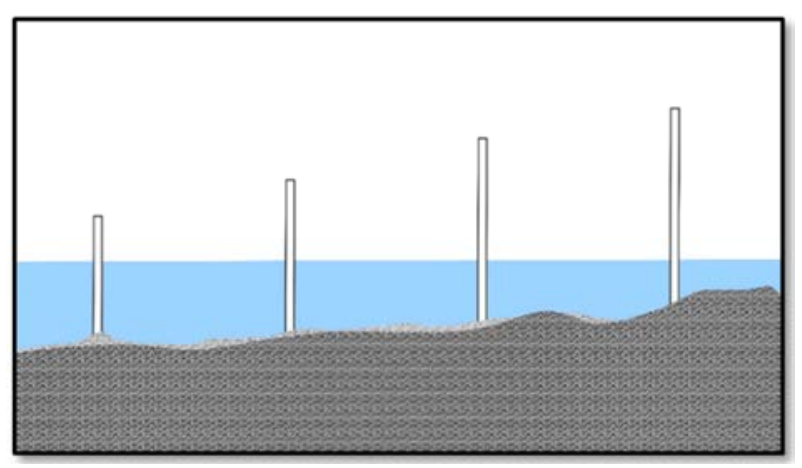

Figure 2. Sedimentary sampling schemes.

This device has been used to record the evolution of sedimentation. it raised theheight of sediment deposited on the bottom of streams after the water flowed. The PVC tubes are graduated to the millimeter to facilitate reading the operator. They are $150 \mathrm{~cm}$ high and are $2.5 \mathrm{~m}$ apart as described on (Figures 2 and 3 ).

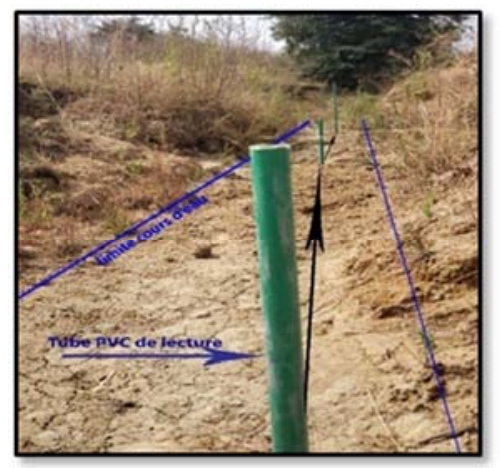

Figure 3. Device implanted in a stream.

Porosity: The saturation method is the one used to determine the porosity of our samples.

It is given by:

$$
\operatorname{porosity}_{(p t)}=\frac{\text { pore volume }_{(v p)}}{\text { total volume }_{(v t)}}
$$

Where

$v t=$

solidvolume +

watervolume (in the saturated sample)

\subsection{Numerical Modeling of Sedimentation}

\subsubsection{Equations of Shallow-water and Exner}

The Shallow-water-Exner Coupled Equation [10-12] is a hyperbolic system composed of the Shallow-water equation, for liquid flow, and the Exner equation for solid flow [9]. In one dimension the equation is as follows:

$$
\left\{\begin{array}{c}
\partial_{t} h+\partial_{x}(h u)=0 \\
\partial_{t}(h u)+\partial_{x}\left(h u^{2}+\frac{g h^{2}}{2}\right)=-g h \partial_{x}(z+H)-g h s_{f} \\
(1-p) \partial_{t} z+\partial_{x} q=0
\end{array}\right.
$$

1) $h(x, t)$ water height in meters $(m)$

2) $(\mathrm{H})$ the height of the non-eroded layer $(\mathrm{m})$

3) g gravity constant or gravitational field $\left(\mathrm{m} / \mathrm{s}^{2}\right)$

4) hu specific flow $\left(\mathrm{m}^{2} / \mathrm{s}\right)$

5) $1 / 2 * \mathrm{gh}^{2}$ hydrostatic pressure

6) Sf represents the friction

7) $z(x, t)$ is the height of sediments expressed in meters (m)

8) $\mathrm{q}(\mathrm{x}, \mathrm{t})$ is the flow of sediment $(\mathrm{kg} / \mathrm{s})$

The flow q is often defined by empirical laws. In our case, we will use the Grass model

$$
\text { Grass (1981) } q=A_{g}|U|^{m g-1} u
$$

1) p is the porosity of the sediments

2) $A_{g}$ measures the interaction between sediments and water If it is close to 0 the interaction is weak. If it close to 1 then the interaction is strong.

3) $\mathrm{m}_{\mathrm{g}}$ can take values $1,2,3, \ldots$ 
Conservative Form:

$$
\partial_{t} W+\partial_{x} F(W)=S(W)
$$

Where

$$
W=\left(\begin{array}{c}
h \\
h u \\
z
\end{array}\right), F(W)=\left(\begin{array}{c}
h u \\
h u^{2}+g \frac{h^{2}}{2} \\
q
\end{array}\right), S(W)=\left(\begin{array}{c}
0 \\
-g h \partial_{x}(z+H) \\
0
\end{array}\right)
$$

Non-conservative form

$$
\begin{aligned}
& \partial_{t} W+A(W) \partial_{x} W=0
\end{aligned}
$$

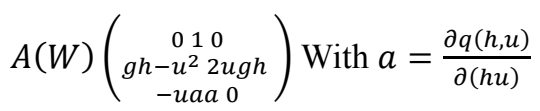

$$
\begin{aligned}
& Z_{i-1} \\
& \mathrm{~h}_{\mathrm{i}-1} \quad \mathrm{u}_{\mathrm{i}-1 / 2}
\end{aligned}
$$

\subsubsection{Digital Resolution of the Equations of \\ Shallow-water-Exner $1 D$}

The finite volume method (figure 4) is used to resolve the coupled equation. It is based on two main steps: the discretization of the space domain into a finite number of control volumes, and the integration of the system of equations considered on each control volume. We denote $\Omega$ $(0, \mathrm{~L})$ and the temporal domain $(0, \mathrm{~T})$. The time intervals are divided into $\mathrm{N}_{\mathrm{t}}$ time steps of $\Delta \mathrm{t}$ length. The $\Omega$ domain is divided into Nx cells of $\Delta x$ length. The far left, the center and the far right of the cell are given by $x_{i-1 / 2}, x_{i}$ et $x_{i+1 / 2}$.

The height of the water (h) and the sediment layer $(\mathrm{z})$ are discretized in the center of the cell.

The speed $\mathrm{u}$ is discretized between the terminals of the cell.

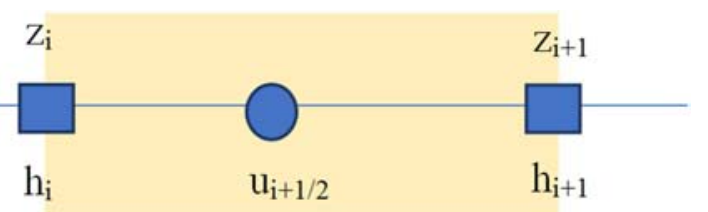

Figure 4. Geometry mesh.

The one-dimensional staggered grids. The green area represents the control volume for the mass conservations, associated with unknowns hi and zi. The control volume for the momentum conservation (unknown ui+1/2) is shown by the yellow area.

Discretization

The numerical solution on the cell $I_{i}$ at the time $t_{n}$ is referred to by:

$$
W_{i}^{n}=\frac{1}{\Delta x} \int_{x_{i-1 / 2}}^{x_{i+1 / 2}} W\left(x, t_{n}\right) d x
$$

\section{Results}

\subsection{Flood Flows from the Lowland Area}

Result in Table 1 gives the floods generated by the maximum rain, recorded during the 2019 campaign. The RATIONAL method gives us the higher flow value of $18.29 \mathrm{~m}^{3} / \mathrm{s}$.

Table 1. Results of flood flow.

\begin{tabular}{lll}
\hline \multirow{2}{*}{ Lowland } & Ten-year floods $\left(\mathbf{m}^{3} / \mathbf{s}\right)$ & \\
\cline { 2 - 3 } & ORSTOM Method & RATIONAL method \\
\hline Sindou & 17.99 & 18.29 \\
\hline
\end{tabular}

Stream flows

Table 2 above shows the results of the flow calculated using Manning Strickler's empirical formula. For a roughness of 22.73 the flow rate is $1.23 \mathrm{~m}^{3} / \mathrm{s}$.

Table 2. Characteristics values of stream flow.

\begin{tabular}{lllllll}
\hline LOCALITY & Section $(\mathbf{m} 2)$ & Perimeter $(\mathbf{m})$ & Friction $(\mathbf{k s})$ & Hydraulic radius $(\mathbf{m})$ & Flow $\left(\mathbf{m}^{3} / \mathbf{s}\right)$ & Speed $(\mathbf{m} / \mathbf{s})$ \\
\hline SINDOU & 0,60 & 2,46 & 22,73 & 0,25 & 1,23 & 1,46 \\
\hline
\end{tabular}

\subsection{Physical Characteristics of Transported Sediments}

The results of the analyses carried out in the civil engineering laboratory of the $2 \mathrm{iE}$ Institute from the collected sediments are in table 3 . The porosity of the sediments transported from Sindou is around 33.07.
Table 3. Results of Stream Porosity Values.

\begin{tabular}{ll}
\hline & SINDOU $(\%)$ \\
\hline TOTAL POROSITY & 33,07 \\
SOIL TYPE & Sandy soil \\
\hline
\end{tabular}

Sensitivity analyses of parameters used in digital modeling The sensitivity analysis in our study will aim to determine 
the influence of friction parameters, parameter $A_{g}$, and of topography, in the model simulation. This will involve varying the values of our input parameters while leaving all other input parameters at their nominal value (figures 5, 6, 7).

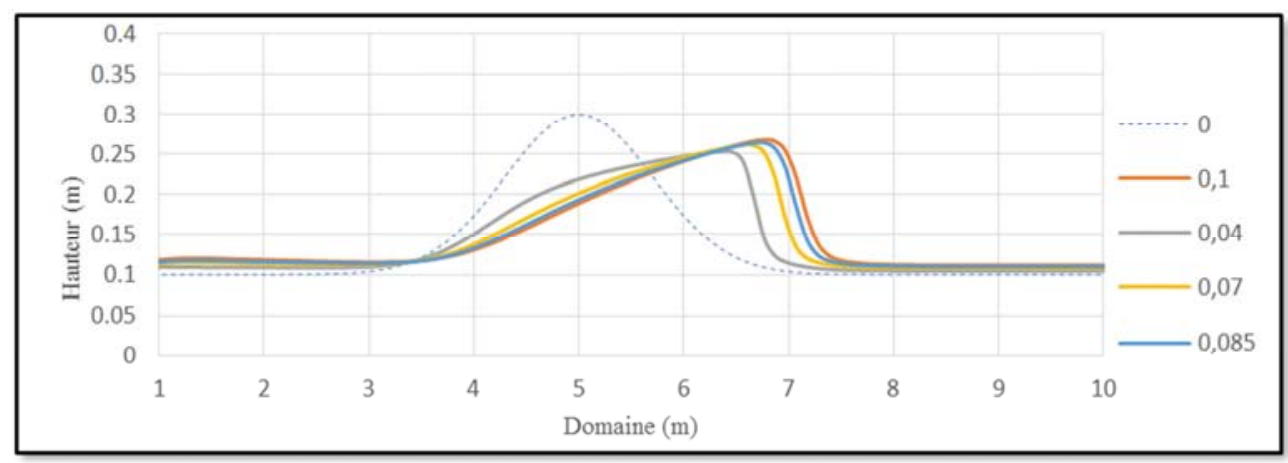

Figure 5. Result of the sensitivity of the modelto the fluid-sediment interaction $\left(A_{g}\right)$.

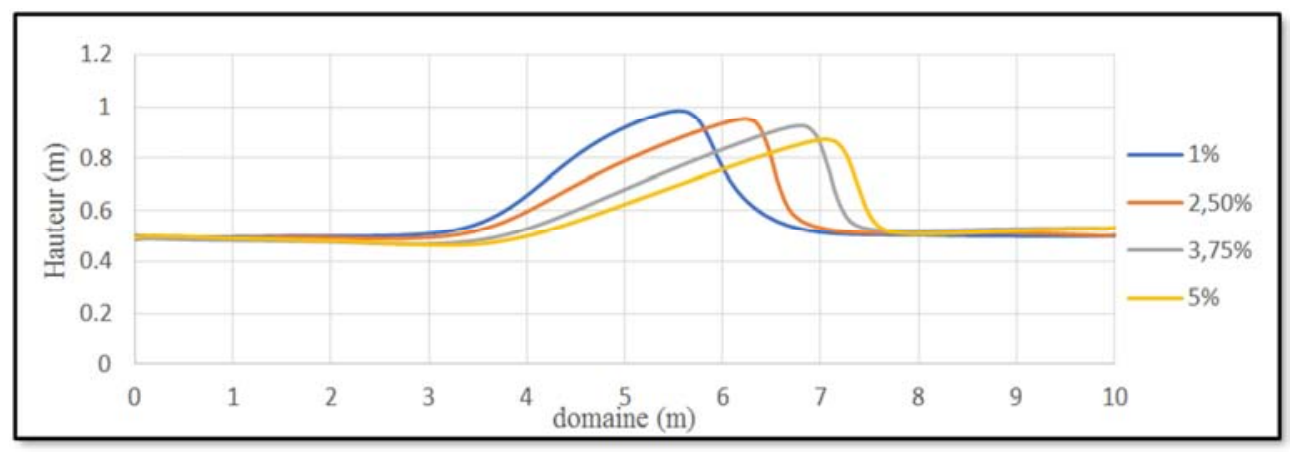

Figure 6. Result of the Sensitivity of the Model to Topography.

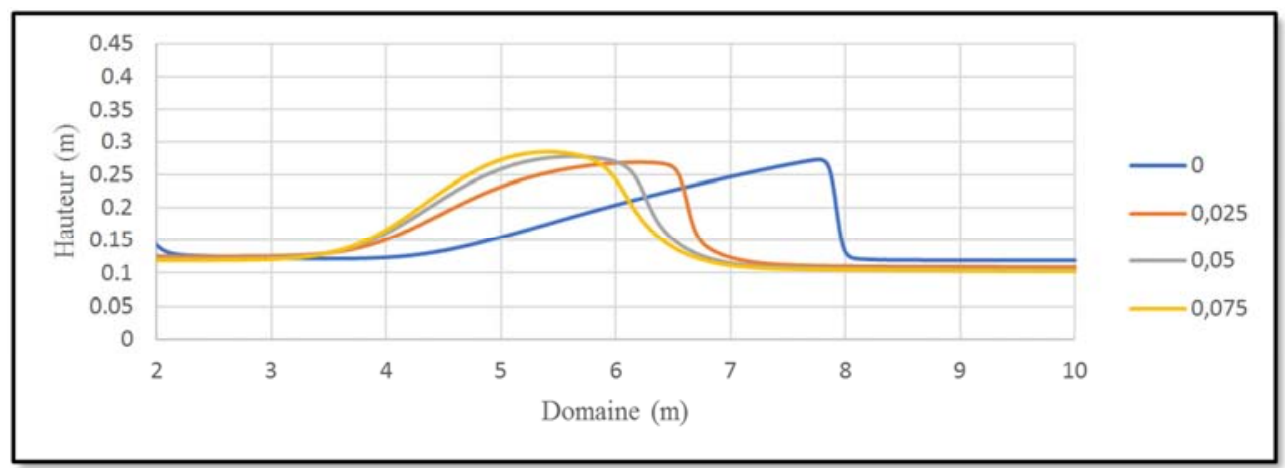

Figure 7. Result of the Sensitivity of the Model to Friction.

\section{Discussion}

Based on the results of the sensitivity analysis of the friction parameters, topography and Ag parameter, the result observed in the (Figure 5) reveals that when the value of the Ag parameter is high the sediment is transported over a longer distance. Our results agree perfectly with those obtained by Gunawan [13]. The same is true for topography sensitivity analysis (Figure 6), which when the slope is increasing, the sediments are transported over a long distance. This influence of the non-erodible background, was obtained by some research [14]. Asfor friction, The results obtained in
(Figure 7) let us see that the greater the value of friction, the less sediment is transported over a long distance. The results of the above sensitivity analysis refer to the results of the studies carried out By authors who worked on friction sensitivity $[15,16]$.

Simulation of the actual case of sedimentation in streams

Previous sensitivity analysis (figures 8, 9) of the parameters shed light on the impact they could have on sediment transportation. So in this part, we will simulate some real cases of sedimentation. The data used for the simulation of the actual case were collected from the Sindou site to dates $(08 / 05 / 2019,08 / 13 / 2019$ and $09 / 15 / 2019)$. 


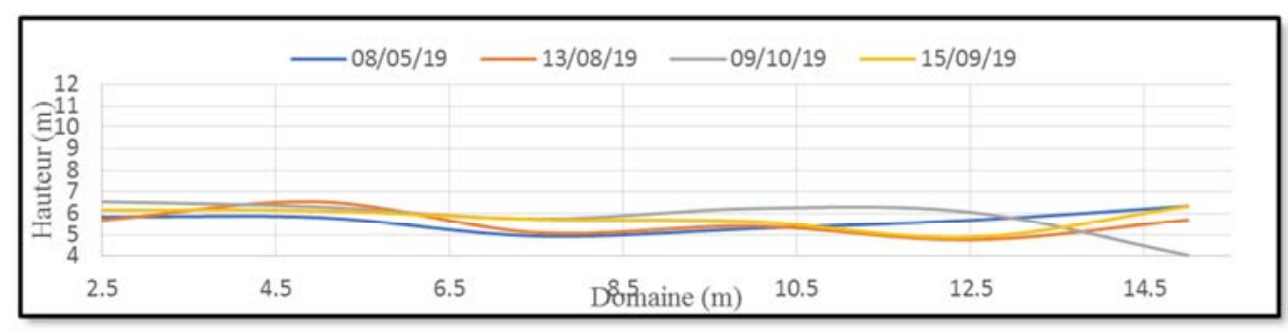

Figure 8. Distribution of sediment from streams on the lowland (Sindou).

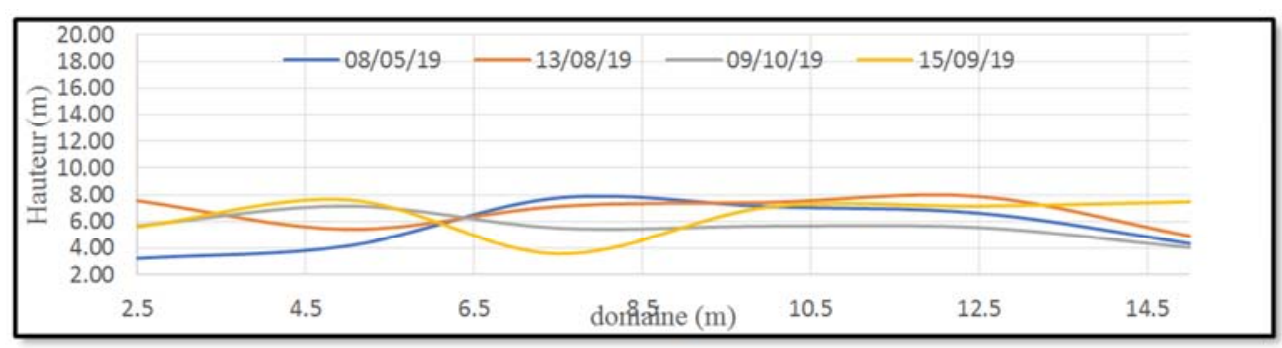

Figure 9. Distribution of sediments collected from the stream at the lowland entrance (Sindou).

The (figures 8, 9) present the results of sediment data collected from the various tubes in the Sindou's zone. Each curve represents the interpolation of discrete values raised by each tube along the entire length of the domain at a given date. We can observe here that there is a difference in the amplitude of the two domains This is explained by the fact that the river upstream of the lowlands released as much sediments as that they receive because of their depressive topography. This is not the case with lowlands which receive more sediment than they release; this promotes an accumulation of sediments materializing by dunes.

In the simulation presented in the (figure 10) the initial conditions were set with the elements observed in the site on08/13/2019 while linking the two domains.

For the boundary conditions, we considered sediment inputs according to the direction of the flow equal to zero, in order to study their behavior in our domain. The similarities in the sedimentation process observed show us that the model has the ability to reproduce this real event.

But we note several differences in the shape of the carried sediments curves, which are due to the fact that the topography of the river in the model, which are derived from synthetic data, and the parameters which led to the determination of friction are not experimental.
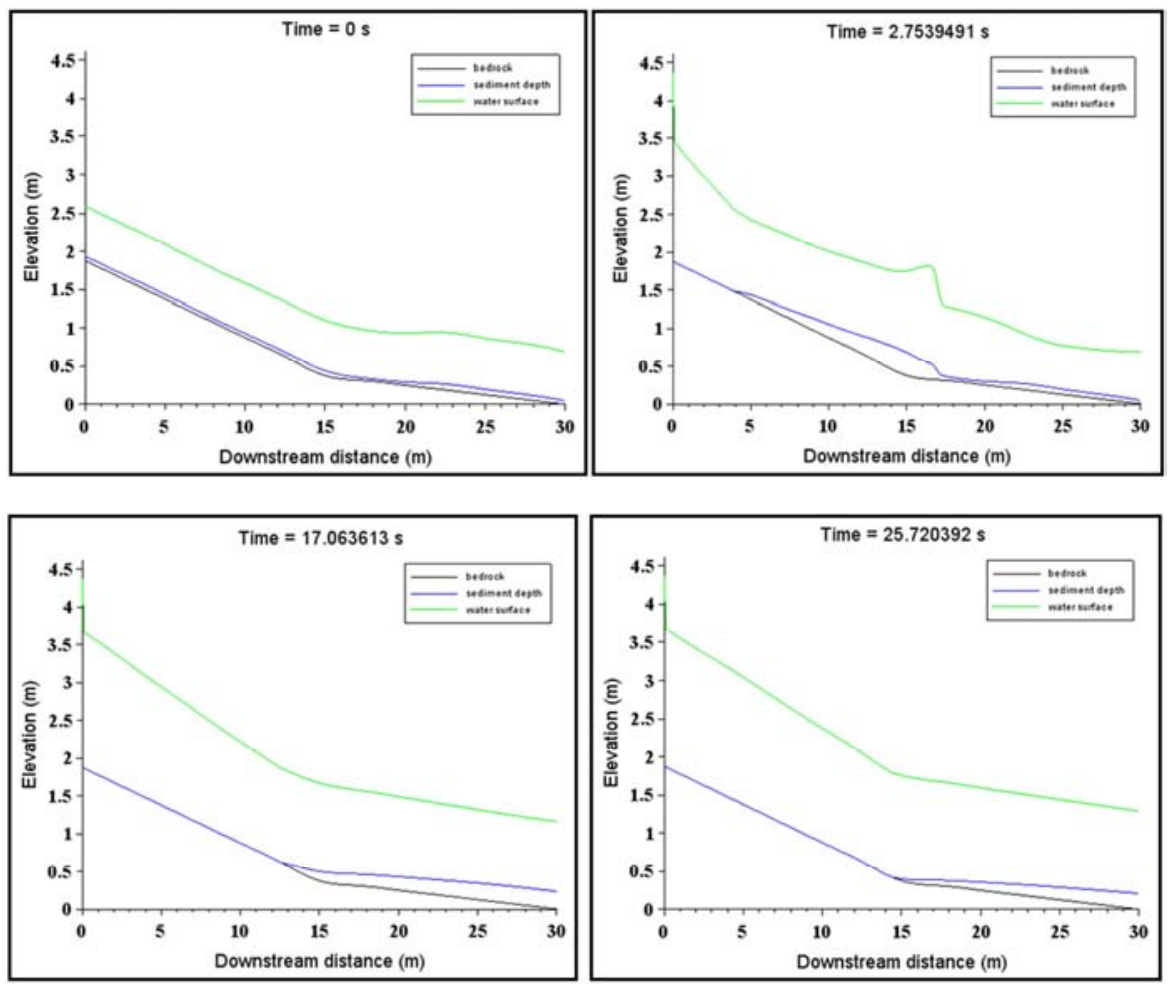

Figure 10. Result of sedimentation in the Sindou river on08/05/2019 in Scilab software. 


\section{Conclusion}

Overall, we have been working on the implementation of a simulation tool to predict sedimentation at the river. The approach was to solve the equation of Shallow-water-Exner which better deals with the issue of sedimentary transport. At the end of our study, the physical characteristics of the sediments and the numerical modelling of the streams were carried out. The model of this study gave us good results in the sensitivity analysis, using synthetic values. Moreover, the simulation of the actual cases aimed at validating the model was unfortunately not very satisfactory. The absence of topographical data and the misrepresentation of friction parameters, and the calculations of flows that were essentially from synthetic data led to poor behavior of our model. For research perspectives, and from the perspective of model validation, we recommend for the simulation of real cases, the consideration of the topographical parameters of streams and the use of more appropriate sedimentation measurement instruments.

\section{Acknowledgements}

This research was funded by the German Development Cooperation (GIZ) through the "Climate-smart rice technologies to enhance resilience of smallholder rice farmers in Burkina-Faso" (CSA-Burkina) project.

\section{References}

[1] M. Hotte et M. Quirion, "Guide technique no 15. Traverses de cours d'eau", p. 131-140, 2003.

[2] P. Bernatchez, "Caractérisation côtière du territoire de la Table de concertation régionale, zone de Québec", p. 78-80, 2016.

[3] J. Somda, "Valeur économique de la vallée du Sourou: Evaluation préliminaire". IUCN, p. 157-159, 2010.

[4] E. V. NGNEPI TOUKEP, “Conception et aménagement de bas-fonds en zone Soudano-sahélienne selon la technologie smart-valleys: cas de barjongo et tensega au Burkina Faso". Ouagadougou, BURKINA FASO, p. 37-38, 2019.

[5] M. GNANE, "Conception et réalisation participatives d'aménagements de bas-fonds suivant l'approche smartvalleys en zone sud soudanienne: cas des sites pilotes de Sindou et de Banflagoue-fon au Burkina Faso". Ouagadougou, BURKINA FASO, p. 24-25, 2018.
[6] Bama Nati Aïssata Delphine, Niang Dial, Gbané Mahama, Ouedraogo Ibrahima, Boube Bassirou, and Ngnepi Toukep Elvire Vanessa, 2019. "Adaptation and Resistance of Smart Valleys Bunds in Sudanians' Lowland: Experience in Four Lowlands in Burkina Faso." American Journal of Water Resources, vol. 7, no. 2 (2019): 58-61. doi: 10.12691/ajwr-72-3.

[7] Africa Rice Center (Africa Rice).2017. http://www.africaricecenter.org. The manual, developed by $\mathrm{T}$ Defoer, M-J Dugué, M Loosvelt and S Worou, is available in English and French. It is supported by the film "Smart-valleys.

[8] Fashola, OO, Olaniyan, G, Aliyu, J et Wakatsuki, T 2002, Comparative evaluation of farmers' paddy field system and the SAWAH system for better and sustainable rice farming in inland valley swamps of Nigeria, in 5th African Crop Science Conference proceedings, pp. 615-619.

[9] D. A. Lyn et M. Altinakar, "St. Venant-Exner equations for near-critical and transcritical flows", J. Hydraul. Eng., vol. 128, n $^{\circ} 6$, p. 579-587, 2002.

[10] S. Martínez-Aranda, J. Murillo, et P. García-Navarro, "Coupled method for the numerical simulation of 1D shallow water and Exner transport equations in channels with variable cross-section", in E3S Web of Conferences, 2018, vol. 40, p. 05012 .

[11] M. C. D1, E. D. Fernández-Nieto, A. Ferreiro, C. Parés, et others, «Two-dimensional sediment transport models in shallow water equations. A second order finite volume approach on unstructured meshes», Comput. Methods Appl. Mech. Eng., vol. 198, n 33-36, p. 2520-2538, 2009.

[12] E. Meyer-Peter et R. Müller, "Formulas for bed-load transport", in IAHSR 2nd meeting, Stockholm, appendix 2, 1948, p. 130.

[13] H. P. Gunawan, "Numerical simulation of shallow water equations and related models". Paris Est, p. 146-148, 2015.

[14] E. D. Fernández-Nieto, T. M. de Luna, G. Narbona-Reina, et J. de Dieu Zabsonré, "Formal deduction of the Saint-VenantExner model including arbitrarily sloping sediment beds and associated energy", ESAIM Math. Model. Numer. Anal., vol. $51, \mathrm{n}^{\circ} 1$, p. $115-145,2017$.

[15] R. Abrahami, «Erosion et flux sédimentaires associés dans un bassin versant soumis à un régime de mousson: l'exemple de la Tista (Inde), du Sikkim au mégafan”, p. 321-326, 2015.

[16] P. Ung, «Simulation numérique du transport sédimentaire: aspects déterministes et stochastiques». p. 271-278, 2016. 